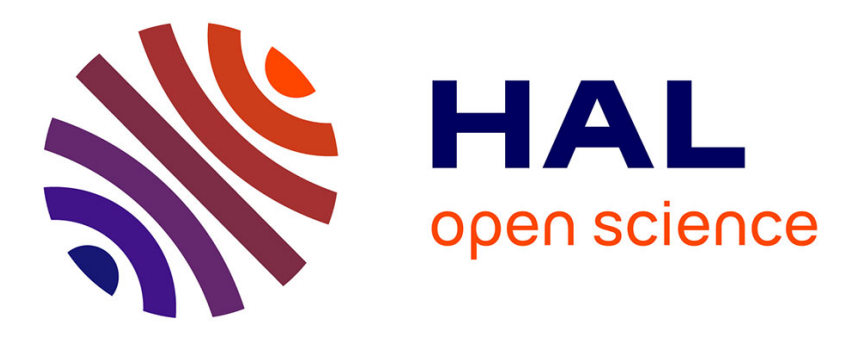

\title{
Exploring the Complexation of Counterion in Novel Family of Polyelectrolytes with Unexpected Solubility Behaviour
}

\author{
Egor A Bersenev, Alina V Maryasevskaya, Evgenii V Komov, Denis V
}

Anokhin, Dimitri Ivanov

\section{To cite this version:}

Egor A Bersenev, Alina V Maryasevskaya, Evgenii V Komov, Denis V Anokhin, Dimitri Ivanov. Exploring the Complexation of Counterion in Novel Family of Polyelectrolytes with Unexpected Solubility Behaviour. Key Engineering Materials, 2020, 869, pp.61-68. 10.4028/www.scientific.net/KEM.869.61 . hal-03095888

\section{HAL Id: hal-03095888 \\ https://hal.science/hal-03095888}

Submitted on 7 Jan 2021

HAL is a multi-disciplinary open access archive for the deposit and dissemination of scientific research documents, whether they are published or not. The documents may come from teaching and research institutions in France or abroad, or from public or private research centers.
L'archive ouverte pluridisciplinaire $\mathbf{H A L}$, est destinée au dépôt et à la diffusion de documents scientifiques de niveau recherche, publiés ou non, émanant des établissements d'enseignement et de recherche français ou étrangers, des laboratoires publics ou privés. 


\section{Exploring the complexation of counterion in novel family of polyelectrolytes with unexpected solubility behaviour}

Egor A. Bersenev ${ }^{1,2} \mathrm{a}^{*}$, Alina V. Maryasevskaya ${ }^{1,2,3, \mathrm{~b}}$, Evgenii V. Komov ${ }^{2,3, \mathrm{c}}$ Denis V. Anokhin ${ }^{1,2,3, \mathrm{~d}}$ and Dimitri A. Ivanov ${ }^{1,2,3,4, e}$

${ }^{1}$ Institute of Problems of Chemical Physics, Russian Academy of Sciences, Semenov Av. 1, Chernogolovka, Moscow region, 142432, Russia

${ }^{2}$ Moscow Institute of Physics and Technology, Institutskiy per. 9, Dolgoprudny, 141700, Russia

${ }^{3}$ Lomonosov Moscow State University, Faculty of Fundamental Physical and Chemical Engineering, GSP-1, 1-51 Leninskie Gory, Moscow, 119991, Russia.

${ }^{4}$ Institut de Sciences des Matériaux de Mulhouse-IS2M, CNRS UMR 7361, F-68057 Mulhouse, France;

abersenev.ea@mipt.ru, balina.maryasevskaya@yandex.ru, cevgenkomov@gmail.com, ddeniano@yahoo.com, edimitri.ivanov.2014@gmail.com

Keywords: polyelectrolytes, infrared spectroscopy, X-ray diffraction, ultrafast chip calorimetry

\section{Abstract}

In the present paper we study the effect of complexation in linear negatively charged polyelectrolytes with different alkali ions. With combination of IR-spectroscopy, X-ray diffraction and nanocalorimetry, we attempted to explain unusual solubility, crystallinity and thermal stability of these polymers. The increase of thermal stability and insolubility in water in series of semi-crystalline polysalts as $\mathrm{K}+\leq \mathrm{H}+<\mathrm{Na}+$ was explained by effectiveness of formation of chelating complex. Insoluble in water sodium salt shows the highest thermal stability of crystal phase up to $270^{\circ} \mathrm{C}$. In contrast, well soluble in water amorphous lithium salt does not self-organize in chelating complex and is presented in ionic form.

\section{Introduction}

In recent decades, the volume of drinking water has been steadily declining due to uncontrolled glacier melting, pollution of waste water and the atmosphere, forest decline, etc. [1]. To solve the problem, new efficient and cost-effective technologies of production and purifying fresh water from seawater, brackish groundwater and waste water are being developed. [2].

Besides, attention grows to the processing of municipal and industrial wastewater that is now perceived as a renewable resource from which nutrients (e.g., phosphate and nitrogen), energy and substances such as bioplastics can be extracted $[3,4]$. In the coming decades, the renewal of resources will be significantly related to wastewater treatment and the advanced separation technologies will be needed.

Polyelectrolyte is the key component in traditional membrane-based methods of water treatment and desalting by micro- and ultrafiltration, as well as by direct and reverse osmosis processes. However, the efficiency and selectivity of existing polyelectrolytes with respect to most alkaline ions such as lithium, potassium and sodium is unsatisfactory.

Well known that charged macromolecules play an important role as building unit for supramolecular self-assembly, exhibiting combination of various noncovalent interactions, such as electrostatic, Wander-Waals or hydrogen bonding [5]. Self-assembly of polyelectrolytes can be used for fabrication of 
thin layers on charged surfaces [6,7], as mediator in electrosynthesis [8] and as flocculating agent in waste water treatment [9].

Recently, new family of poly(trimethylene-1,1-dicarboxylate) (PTMDC) polyelectrolytes with two substituents at every third carbon atom in the main chain was synthesized [10] and studied $[11,12]$. Those materials with symmetrical structure of main chain show relatively high crystallinity of reactor powder (app. 25\%) and their alkali salts exhibit unusual solubility behavior, namely, reversible and selective precipitation in the presence of sodium ions. Selective sodium ion coupling in solution remains an interesting chemical challenge and can find application in water desalination and purification. The most of typical polyelectrolytes do not exhibit selective interaction with alkali cations. However, for polyacrylic acid was reported a small effect of counterion on solubility [13].

Preliminary studies of the PTMDC structure reveal very similar structure for polyacid, sodium and potassium polysalts [14]. Solubility in water decrease as $\mathrm{K}+>\mathrm{H}+>\mathrm{Na}+$ where sodium salt is almost insoluble. NMR results suggest formation of three structures of these polyelectrolytes: crystalline, "dimer" and "oligomer" phase [15]. Formation of such phases can be attributed to symmetrical architecture of those polymers. However, direct correlation between complexation of the poly(trimethylene-1,1-dicarboxylate) polyelectrolyte and its crystal structure has not been revealed.

TGA experiment on slow heating of all salts demonstrate $5 \%$ loss of weight at $100^{\circ} \mathrm{C}\left(\mathrm{H}_{2} \mathrm{O}\right.$ loss $)$ followed by $30 \%$ loss of $\mathrm{CO}_{2}$ resulting in decarboxylation [15]. The decarboxylation causes amorphization of the samples without crystal phase melting. Since detachment of carboxylic group is relatively slow process, thermodynamic melting can be reached by increase of heating rate using nanocalorimetry technique. Earlier, we have approved this method in thermal analysis of energetic materials and semirigid-chain polyesters [16-18]. Microparticles of the material was studied during ultrafast heating/cooling (up to $10^{5}{ }^{\circ} \mathrm{C} / \mathrm{s}$ ) ramps, which allows separating different thermal events such melting, recrystallization, evaporation and chemical decomposition.

In the present contribution, we address structure of poly(trimethylene-1,1-dicarboxylate) polyelectrolyte directly by combination of synchrotron-based temperature-resolved X-ray diffraction, infrared spectroscopy and ultrafast chip nanocalorimetry methods in order to enlighten structure and thermal behavior of PTMDC polyacid and alkali salts.

\section{Materials and methods}

Poly(trimethylene-1,1-dicarboxylate lithium) was synthesized by ring-opening polymerisation followed by hydrolysis of ester and ion exchange reaction as described in previous publications $[10,14]$. Polyacid was obtained from lithium salt using an ion exchange column loaded with the cation exchange resin Amberlite IR $120 \mathrm{Na}$. The $0.1 \mathrm{M} \mathrm{HCl}$ solution was passed through the column followed by distilled water until a neutral $\mathrm{pH}$ was reached. After that, the solution of lithium salt was passed through the column, and the result of ion exchange was registered by the $\mathrm{pH}$ shift from neutral to acidic. The resulting aqueous solution was dried in a lyophilizer and a white powder was obtained. The product yield was approximately $40 \%$. Sodium and potassium salts were obtained by addition of excess of respective hydroxide [14]. In further discussion polyacid, lithium, sodium and potassium salts ate noted as $\mathrm{H} 2, \mathrm{Li} 2, \mathrm{Na} 2$ and $\mathrm{K} 2$, respectively.

X-ray diffraction (XRD) experiments were carried out at the BM26 beamline of European Synchrotron Radiation Facility (ESRF) in Grenoble, France (wavelength $\lambda=0.99 \AA$ ) and on laboratory SAXS/WAXS machine Xeuss (Xenocs) coupled to a GeniX 3D generator ( $\lambda=1.54 \AA$ ). Temperatureresolved experiments were performed using Linkam DSC600 heating stage with heating rate $10 \mathrm{~K} / \mathrm{min}$. Exposure time during heating was $5 \mathrm{sec}$. Modulus of scattering vector $\mathrm{q}\left(|q|=\frac{4 \pi \cdot \sin (\theta)}{\lambda}\right)$, 
where $\theta$ is the Bragg angle, was calibrated using several reflections of $\mathrm{Al}_{2} \mathrm{O}_{3}$ powder. $\mathrm{X}$-ray patterns were recorded using Pilatus 300kw position-sensitive detector at BM26B and Rayonix HS-170 CCD detector in laboratory machine. X-ray data reduction and analysis were performed using pyFAI[19] routine and homemade Python procedures.

Crystal size $l$ was calculated according to Scherrer's formula:

$$
l=\frac{2 \pi}{\Delta q}
$$

where $\Delta q$ - integral half-width of corresponding crystal peak from I(q) dependence.

IR spectra were collected using a Bruker Alpha FTIR spectrometer in the range $4000 \mathrm{~cm}^{-1}-360 \mathrm{~cm}^{-1}$ with a resolution of $4 \mathrm{~cm}^{-1}$ in transmission geometry. Samples were pressed into $\mathrm{KBr}$ pellets. Results were averaged over 64 scans.

Nanocalorimetry method was applied for analysis of thermal behaviour of PTMDC microparticles during ultrafast heating and cooling. The experiment was performed on home-built Nanocalorimeter at heating rate $500{ }^{\circ} \mathrm{C} / \mathrm{s}$. The microparticles were placed with the help of a micromanipulator on the XEN-393 nanocalorimetric sensors (Xensor Integration, Netherlands) with active area of 100x100 $\mu \mathrm{m}^{2}$. Then the chip was connected to electronic block of the device, and by setting a certain type of thermal program in the software interface, diagrams of dependence of specific temperature difference between an empty sensor and a sensor with a sample on temperature were obtained. For better understanding of thermal processes, we use Carl Zeiss Axio Scope A1 polarizing optical microscope equipped with digital high-speed Phantom Miro C110 camera, which allows to record black and white images with a resolution of $1280 \times 720$ pixels. Recording starts by triggering from Nanocalorimeter heaters, the frame rate was $300 \mathrm{~Hz}$.

\section{Results and discussion}

To explain unusual solubility pattern, we have focused on study of the COO-group oscillation as it may reveal the nature of counter ion bonding. Structure of such complex is well studied by various groups [20,21]. They suggest formation of four types of bonding in COO- complexes: ionic, unidentate, bidentate or chelating and bridging complexes. Peak position of COO- vibration may vary significantly with the change of counter-ion, however, difference between symmetric and antisymmetric modes $\Delta$ remains almost constant for a certain type of coupling. In general, we suggest that unidentate complexes exhibit much greater $\Delta$ values than ionic ones. In contrast, for chelating complexes $\Delta$ values that are significantly less than the value for ionic structure.

For Na2, K2 and H2 samples we observe two pairs of peaks corresponding to COO- vibrations: one very strong band at ca. $1750 \mathrm{~cm}^{-1}$ to antisymmetric vibration of COO- group, shoulder at $1640 \mathrm{~cm}^{-1}$ could be attributed to $\mathrm{HOH}$ bending of lattice water. Symmetric vibration corresponding to this type of coupling is located around $1220 \mathrm{~cm}^{-1}$. Another two peaks of COO- vibrations found in those samples are significantly less intense. First band at $1459 \mathrm{~cm}^{-1}$ corresponds to antisymmetric vibration of COO- with chelating complexing of counter-ion and the second band at $1405 \mathrm{~cm}^{-1}$ assigned to symmetric vibration. 


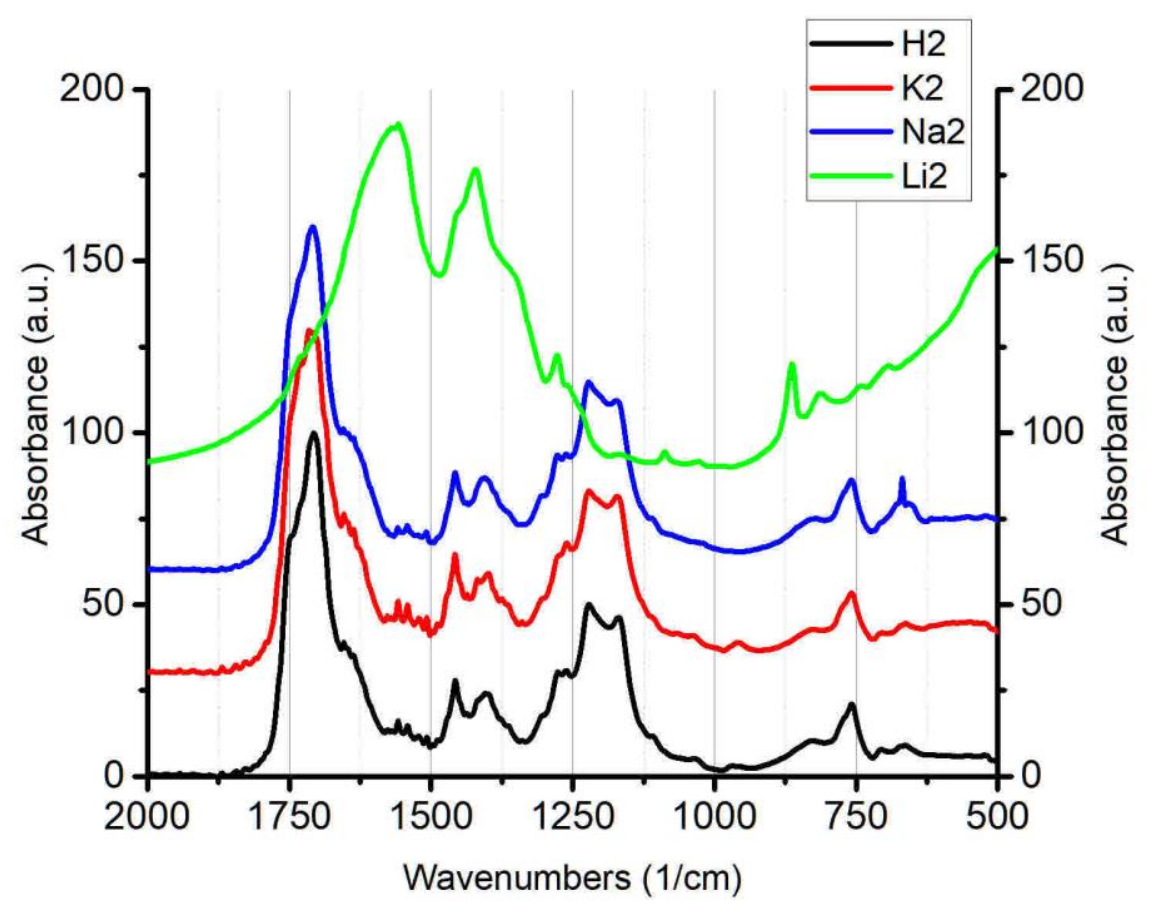

Figure 1. IR spectra of H2 (black), K2 (red), Na2 (blue) and Li2 (green)

IR spectra observed for Li2 polysalt show different structure. We observe two intense absorption bands of symmetric and antisymmetric vibrations located at 1425 and $1560 \mathrm{~cm}^{-1}$, respectively (Fig.1, green curve). Such pattern allows to conclude that lithium salt possesses an ionic uncoordinated form. In addition, all samples exhibit a very broad absorption peak in the region $2800-3600 \mathrm{~cm}^{-1}$, which is "continuous absorption" resulting from hydrogen bonding between water and carboxylic groups.

Table 1. Characteristic IR-absorption bands of the studied samples.

\begin{tabular}{|l|l|l|l|l|}
\hline Sample & \multicolumn{1}{|c|}{$v_{a}, \mathrm{~cm}^{-1}$} & \multicolumn{1}{|c|}{$v_{s}, \mathrm{~cm}^{-1}$} & $\Delta, \mathrm{cm}^{-1}$ & Bonding \\
\hline Li2 & $1560(\mathrm{VS})$ & $1425(\mathrm{VS})$ & 135 & Ionic \\
\hline \multirow{2}{*}{$\mathrm{Na} 2$} & $1459(\mathrm{M})$ & $1405(\mathrm{M})$ & 54 & Chelating \\
\cline { 2 - 5 } & $1708(\mathrm{VS})$ & $1217(\mathrm{~S})$ & 491 & Unidentate \\
\hline \multirow{2}{*}{ K2 } & $1457(\mathrm{M})$ & $1398(\mathrm{M})$ & 59 & Chelating \\
\cline { 2 - 5 } & $1715(\mathrm{VS})$ & $1221(\mathrm{~S})$ & 494 & Unidentate \\
\hline \multirow{2}{*}{$\mathrm{H} 2$} & $1457(\mathrm{M})$ & $1401(\mathrm{M})$ & 56 & Chelating \\
\cline { 2 - 5 } & $1708(\mathrm{VS})$ & $1217(\mathrm{~S})$ & 491 & Unidentate \\
\hline
\end{tabular}

The difference in organization of Li2 and other salts was proved by XRD method. One-dimensional diffractograms of Li2 demonstrate two broad amorphous halos and a set of weak sharp reflection that were attributed to $\mathrm{LiOH}$ crystal phase (Fig.2, green curve). The amorphous state of $\mathrm{Li} 2$ is in agreement with suggestion about uncoordinated structure this salt. Similar uncoordinated bonding was found for sodium polyacrylate that exhibits very similar IR spectra and XRD pattern [22].

XRD patterns of $\mathrm{H} 2, \mathrm{~K} 2$ and $\mathrm{Na} 2$ salts demonstrate relatively sharp reflections and similar crystal structure with degree of crystallinity around $28 \%$ (Fig. 2, Table 2). Crystal size calculated from the most intense peak at $q=1.4 \AA^{-1}$ was found to be app. $7 \mathrm{~nm}$. Small crystal size indicates relatively low degree of polymerisation and formation of extended chain disordered crystals with numerous end groups as structural defects. 


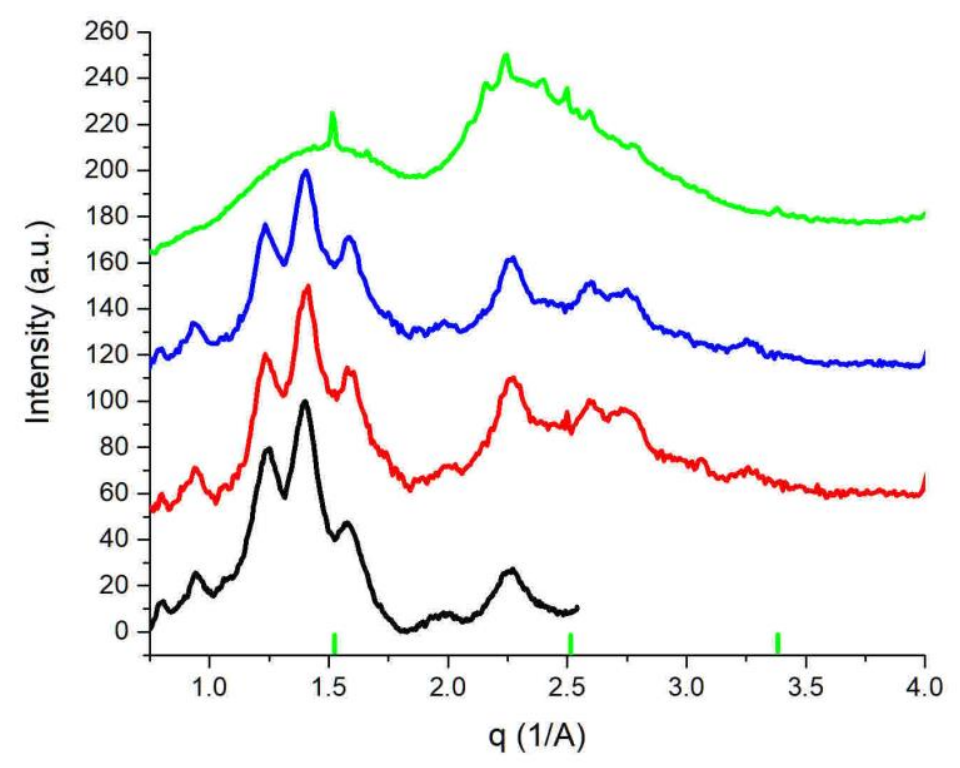

Figure 2. XRD profiles H2 (black), K2 (red), Na2 (blue) and Li2 (green). LiOH reflexes marked with green ticks.

It is noteworthy that semi-crystalline $\mathrm{H} 2, \mathrm{~K} 2$ and $\mathrm{Na} 2$ polysalts exhibit a combination of two types of complexation: crystalline region is formed by chelating complex and mobile amorphous region formed by unidentate complex. Indeed, this correlates well with NMR data on polyacid that demonstrates presence of three peaks: one for crystalline phase and two for "dimer" and "oligomer" amorphous phases, respectively [17]. Calculated degree of crystallinity $-25 \%$, is in good agreement with our XRD results.

Table 2. d-spacings of crystal and amorphous structure of the samples calculated from XRD data.

\begin{tabular}{|c|c|c|c|c|}
\hline Sample & \multicolumn{2}{|c|}{$d_{c r}, \AA$} & $d_{a m}, \AA$ & $l, \AA$ \\
\hline \multirow[t]{2}{*}{ K2 } & 5.09 & 3.98 & \multirow[t]{2}{*}{4.3} & \multirow[t]{2}{*}{72} \\
\hline & 4.47 & 2.76 & & \\
\hline \multirow[t]{2}{*}{$\mathrm{Na} 2$} & 5.09 & 3.98 & \multirow[t]{2}{*}{4.4} & \multirow[t]{2}{*}{70} \\
\hline & 4.47 & 2.76 & & \\
\hline \multirow[t]{3}{*}{$\mathrm{H} 2$} & 6.62 & 3.98 & \multirow[t]{3}{*}{4.6} & \multirow[t]{3}{*}{66} \\
\hline & 5.09 & 3.16 & & \\
\hline & 4.48 & 2.78 & & \\
\hline \multirow[t]{2}{*}{ Li2 } & \multirow{2}{*}{\multicolumn{2}{|c|}{$\mathrm{n} / \mathrm{a}$}} & 4.4 & $\mathrm{n} / \mathrm{a}$ \\
\hline & & & 2.5 & \\
\hline
\end{tabular}

Thermal stability of chelating complex of $\mathrm{H} 2$ was studied by temperature-resolved XDR (Fig. 3). During heating initial 1D XRD pattern stay unchanged with small decrease of crystalline peaks intensity. In the region $140-180^{\circ} \mathrm{C}$ one can observe intensity drastically decreasing and peaks broadening indicating partial amorphization of the polyacid. During subsequent cooling an initial 
crystalline structure does not recover indicating irreversible decarboxylation process occurring over $160{ }^{\circ} \mathrm{C}$ during slow heating.

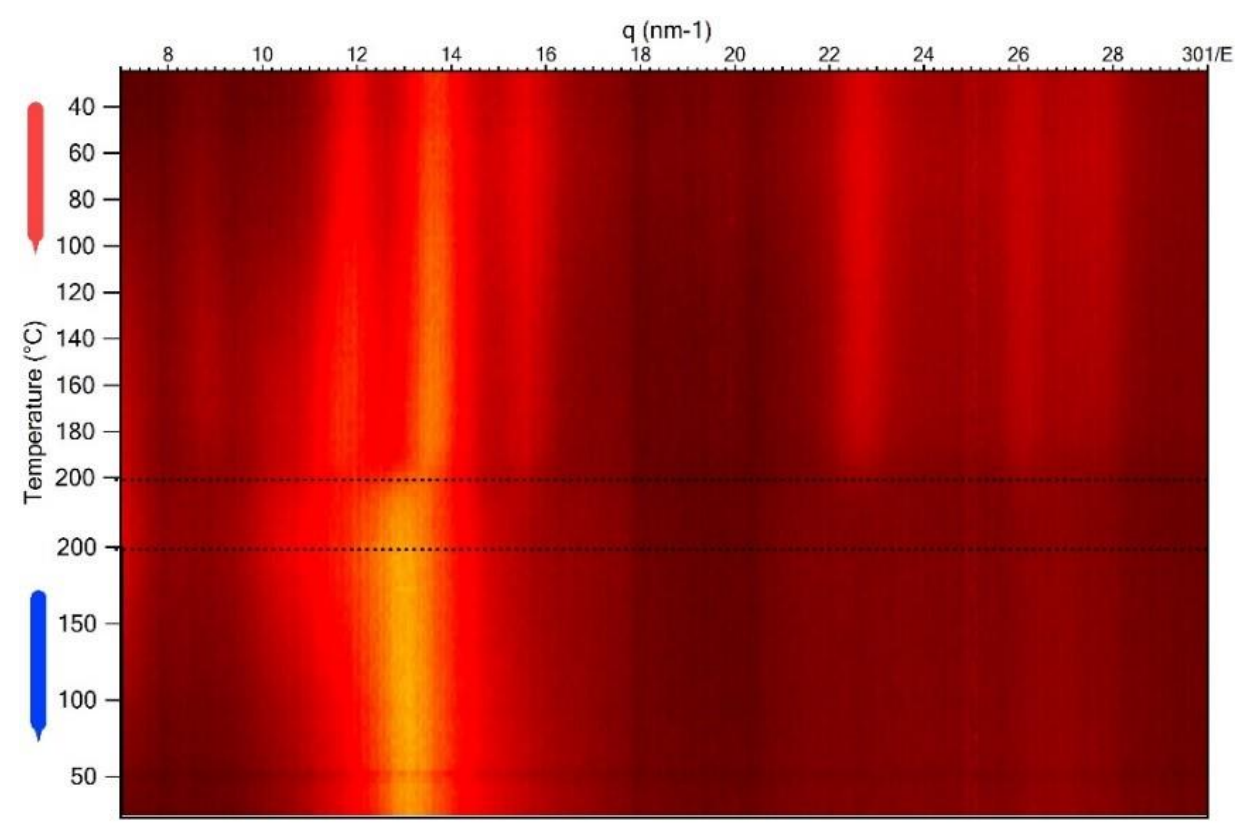

Figure 3. Temperature-resolved XRD of $\mathrm{H} 2$. Red arrow corresponds to heating with $10{ }^{\circ} \mathrm{C} / \mathrm{min}$, blue arrow indicates cooling with $40{ }^{\circ} \mathrm{C} / \mathrm{min}$.

Interesting, that from high-temperature XRD data we cannot see melting point of crystal phase. The reason is that chemical process of decarboxylation occurs in crystalline state before or simultaneously with thermodynamically driven melting. Direct evidence of crystal phase melting was obtained by using the novel nanocalorimetry technique in combination with ultrafast optical microscopy.

In Fig.4, right nanocalorimetric heating curves of polysalts measured at $500{ }^{\circ} \mathrm{C} / \mathrm{s}$ rate are presented. For $\mathrm{H} 2$ sample, we see a weak broad endothermic peak at $200-250^{\circ} \mathrm{C}$ attributed to melting of the crystal phase. Later, at $270^{\circ} \mathrm{C}$ an exothermic step of $\Delta \mathrm{T}$ was revealed (Fig $4 \mathrm{a}$, black curve). This step is associated with decrease of sample heat capacity and indicate loss of weight due to decarboxylation. Similar thermal but with better pronounced peak is shown for K2 microparticle (Fig.4a, red curve). The melting peak is shifted to $120-160^{\circ} \mathrm{C}$ indicating lower thermal stability of crystal phase of potassium polysalt. The decarboxylation process begins at $270^{\circ} \mathrm{C}$ similar to that for $\mathrm{H} 2$. For big $\mathrm{K} 2$ particle the thermal events during heating was visualized with fast camera (Fig.4b). One can see formation of liquid drop during melting (Fig.4b, images 1,2) and gas release at decarboxylation (Fig.4b, image 3). For Na2 microparticle one can see only the step of decarboxylation without endothermic melting peak (Fig.4a, blue curve). Such behavior can be understood from micrographs of $\mathrm{Na} 2$. We see microparticle in crystalline state up to $250^{\circ} \mathrm{C}$ (Fig.4b, images 4,5 ) drop formation immediately followed by gas release, consequently, melting and decarboxylation of $\mathrm{Na} 2$ occur simultaneously above $270^{\circ} \mathrm{C}$ (Fig.4b, image 6). On the nanocalorimetric curve, the intense weight loss process overlaps endothermal melting. In contrast to above-mentioned samples, fast heating of $\mathrm{Li} 2$ reveals endothermic step at $250-300^{\circ} \mathrm{C}$ that can be interpreted as glass transition of the amorphous polymer (Fig.4a, green curve). The reason of the absence of endothermic step could be that decarboxylation for amorphous lithium salt is spread over wide heating range and cannot be visualized as the single $\Delta \mathrm{T}$ step. Another reason is that microparticle of Li2 is decarboxylized at room temperature before heating. In any case, nanocalorimetry data show low thermal stability of Li2 in ionic form. 


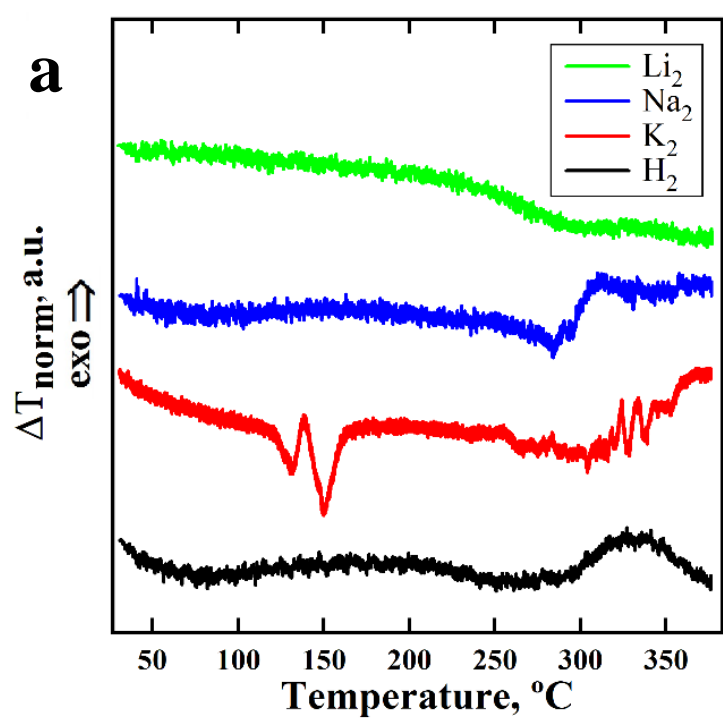

b

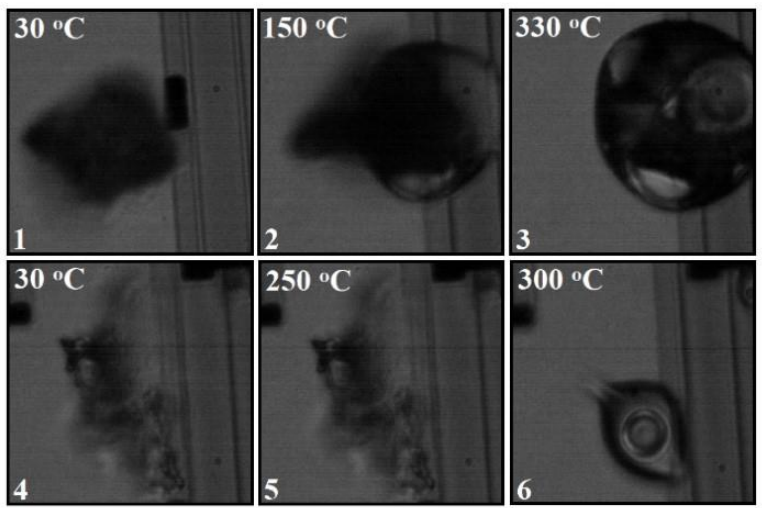

Figure 4. $a$ : nanocalorimetric traces of Li2 (green), Na2 (blue), K2 (red) and H2 (black): $b$ : microphotographs of K2 (images 1-3), Na2 (images 4-6) recorded during fast heating at indicated temperature.

In conclusion, for series of novel symmetric poly(trimethilene-1,1-dicarboxylates) the effect of alkali counterion on complexation, crystallinity and thermal stability was studied. IR-spectroscopy and XRD data show that acid, potassium and sodium salts form chelating type of complex with regular structure that able to form crystal phase. In contrast, amorphous lithium salt is presented in uncoordinated ionic form. After analysis of microparticles with nanocalorimetry it was found that thermal stability of crystal phase correlates well with insolubility in water and increases in series of counterions as $\mathrm{K}+\leq \mathrm{H}+<\mathrm{Na}+$. For the most insoluble sodium salt melting of microparticle occurs simultaneously with decarboxylation above $270^{\circ} \mathrm{C}$. We suppose that this tendency is related to stability of chelating complex, which is the highest for sodium salt. Ionic form of lithium salt stays well soluble in water and show low thermal stability. The obtained results give us an additional insight into the origins of complexations of alkali ions by polyelectrolytes and will help in design of perspective membranes for water purification and metal recovery.

\section{Acknowledgments}

The authors thank Professor Jacques Penelle and Antoine Benlahouès for synthesis of polyelectrolites and for fruitful discussion. The work was done with financial support of Ministry of Science and High Education of Russian Federation (contract № 14.587.21.0052, identifier RFMEFI58718X0052). The work was done on the theme of the state task № 0089-2019-0012 (registration № AAA-A19119032690060-9) and state task 0074-2019-0014 (registration № AAAA-A19-119101590029-0). 


\section{References}

1. Elimelech, M. The global challenge for adequate and safe water. J. Water Supply Res. Technol. - AQUA 55, 3-10 (2006).

2. Shannon, M. A. et al. Science and technology for water purification in the coming decades. Nature 452, 301-310 (2008).

3. Van Loosdrecht, M. C. M. \& Brdjanovic, D. Anticipating the next century of wastewater treatment. Science (80-. ). 344, 1452-1453 (2014).

4. Grant, S. B. et al. Taking the 'waste' out of 'wastewater' for human water security and ecosystem sustainability. Science (80-. ). 337, 681-686 (2012).

7. Macknight, W. J., Ponomarenko, E. A. \& Tirrell, D. A. Self-Assembled Polyelectrolyte Surfactant Complexes in Nonaqueous Solvents and in the Solid State. Acc. Chem. Res. 31, 781-788 (1998).

8. Claesson, P. M., Poptoshev, E., Blomberg, E. \& Dedinaite, A. Polyelectrolyte-mediated surface interactions. Adv. Colloid Interface Sci. 114-115, 173-187 (2005).

9. Bertrand, P., Jonas, A., Laschewsky, A. \& Legras, R. Ultrathin polymer coatings by complexation of polyelectrolytes at interfaces: suitable materials, structure and properties Scheme of the electrostatic layer-by-layer self-assembly (ESA). Macromol. Rapid Commun 21, (2000).

10. Schille, B., Giltzau, N. O. \& Francke, R. Zur Nutzung von Polyelektrolyten und Polymediatoren in der organischen Elektrosynthese. Angew. Chemie 130, 429-433 (2017).

11. Bolto, B. \& Gregory, J. Organic polyelectrolytes in water treatment. Water Res. 41, 2301-2324 (2007).

12. Penelle, J. \& Xie, T. Synthesis, characterization, and thermal properties of poly(trimethylene1,1-dicarboxylate) polyelectrolytes. Macromolecules 34, 5083-5089 (2001).

13. Sikorski, P., Atkins, E. D. T., Kagumba, L. C. \& Penelle, J. Structure and morphology of poly(diethyl trimethylene-1,1-dicarboxylate) crystals. Macromolecules 35, 6975-6984 (2002).

14. Illy, N. et al. Synthesis and Solid-State Properties of PolyC3 (Co)polymers Containing (CH2$\mathrm{CH} 2-\mathrm{C}(\mathrm{COOR}) 2)$ Repeat Units with Densely Packed Fluorocarbon Lateral Chains. Macromolecules 52, 9199-9207 (2019).

15. Axelos, M. A. V., Mestdagh, M. M. \& Francois, J. Phase Diagrams of Aqueous Solutions of Polycarboxylates in the Presence of Divalent Cations. Macromolecules 27, 6594-6602 (1994).

16. Elhalawany, N., Négrell, C., Illy, N., Brissault, B. \& Penelle, J. Preliminary investigations on a simple polyelectrolyte derived from $(\mathrm{CH} 2 \mathrm{CH} 2 \mathrm{C}(\mathrm{COOH}) 2) \mathrm{n}$ : Unexpected solubilityinsolubility pattern controlled selectively by the nature of the alkali counterion. Polymer 116, 515-522 (2017).

17. Benlahouès, A. Développement de méthodologies de synthèse innovantes pour 1 ' obtention de chimiothèques de polyélectrolytes. (2018).

18. Piazzon, N., Rosenthal, M., Bondar, A., Spitzer, D. \& Ivanov, D. A. Characterization of explosives traces by the Nanocalorimetry. J. Phys. Chem. Solids 71, 114-118 (2010).

19. Melnikov, A. P. et al. Re-exploring the double-melting behavior of semirigid-chain polymers with an in-situ combination of synchrotron nano-focus X-ray scattering and nanocalorimetry. Eur. Polym. J. 81, 598-606 (2016). 
20. Melnikov, A. P., Rosenthal, M. \& Ivanov, D. A. What Thermal Analysis Can Tell Us about Melting of Semicrystalline Polymers: Exploring the General Validity of the Technique. ACS Macro Lett. 7, 1426-1431 (2018).

21. Ashiotis, G. et al. The fast azimuthal integration Python library: PyFAI. J. Appl. Crystallogr. 48, 510-519 (2015).

22. Nakamoto, K. Infrared and Raman Spectra of Inorganic and Coordination Compounds, Part $B$. (Wiley).

23. G.B. DEACON and R.J. PHILLIPS. RELATIONSHIPS BETWEEN THE CARBONOXYGEN STRETCHING FREQUENCIES OF CARBOXYLATO COMPLEXES AND THE TYPE OF CARBOXYLATE COORDINATION. Coord. Chem. Rev. 33, 227-250 (1980).

24. Feairheller, W. R. \& Katon, J. E. The vibrational spectra of acrylic acid and sodium acrylate. Spectrochim. Acta Part A Mol. Spectrosc. 23, 2225-2232 (1967). 